\title{
Affectus Hispaniae en la historiografía del Alto Imperio
}

\author{
Antonio Cascón Dorado \\ Universidad Autónoma de Madrid \\ antonio.cascon@uam.es
}

\section{RESUMEN}

Se estudian en este trabajo los textos de historiadores del Alto Imperio, latinos y griegos, que tratan sobre Hispania. En algunos autores encontramos una visión muy positiva (Floro, Justino, Apiano) y en otros claramente negativa (Veleyo Patérculo, Valerio Máximo), aunque en la mayoría de los casos hay escasa atención, indiferencia o diversidad de opiniones. El interés por la región y los elogios pueden estar motivados por el origen hispánico del autor o su voluntad de agradar a algún emperador oriundo de Hispania, pero también por una concepción universal de la historia que denota en ocasiones una posición crítica con el imperialismo romano, como es el caso de Apiano. La alabanza que hallamos en el epítome de Justino creemos que debe atribuirse más al epitomador que a Pompeyo Trogo, lo que apoyaría una datación temprana de la vida y la obra de Justino (s. II d.C.). La aversión hacia Hispania parece haber surgido en medios conservadores, "optimates" nacionalistas, que ven la provincia como el territorio "popular", que encumbró y acogió a "sediciosos" como Tiberio Graco y Sertorio.

Palabras clave: Hispania. Alto Imperio. Historiadores. Nacionalismo. Anti-imperialismo. Optimates. Populares.

\section{Affectus Hispaniae in the Historiographical Work of the Early Empire}

\begin{abstract}
This paper analyses texts written by Greek and Latin High Empire historians dealing with Hispania. Some of the authors have a very positive view (Florus, Iustinus, Appian) while others are clearly negative (Veleius Paterculus, Valerius Maximus) though most of them show little interest, indifference or variety of opinions. When there is interest in the region or praise, it is because the author comes from Hispania or he is trying to please an emperor born in Hispania, but it could also be due to a universal conception of history revealing a critical attitude towards Roman imperialism, as in Appian. The praise found in Iustinus's epitome should be attributed to the author of the epitome rather than to Pompeius Trogus. This can be taken as evidence for situating Iustinus's life and work in the $2^{\text {nd }}$ century A.D. Loathing of Hispania seems to have its origins in conservative, 'optimate' nationalist circles, who perceive the province as the 'popular' region that acclaimed and welcomed 'seditious' individuals such as Tiberius Gracchus and Sertorius.
\end{abstract}

Key Words: Hispania. Early Empire. Historians. Nationalism. Anti-imperialism. Optimates. Populares. 
Pompeyo Trogo, historiador de la época de Augusto, que publicó su obra en los albores de la era cristiana, ${ }^{1}$ escribe en el último libro de sus Historias Filípicas un elogio de Hispania que normalmente se incluye entre las llamadas laudes Hispaniae, textos de diferentes autores clásicos, recopilados a través del tiempo, en los que el país es elogiado por distintos motivos. ${ }^{2}$ La alabanza de Trogo se incluye en el libro LXIV de sus Historias, dedicado íntegramente a Iberia y que constituye, como se ha apuntado, la primera historia general sobre la Península Ibérica. ${ }^{3}$ Aparte de otras cuestiones de interés, el texto es a nuestro juicio importante básicamente por dos motivos: primero porque habla de Hispania como unidad geográfica, étnica y potencialmente política $\mathrm{y}$, en segundo lugar, por la visión tan positiva del país que trasmiten sus palabras. ${ }^{4}$ Dejaremos el primer punto para otro lugar y en las páginas que siguen vamos a ocuparnos fundamentalmente del segundo, intentando averiguar las causas de esa alabanza y poniéndola en relación con las otras laudes y con la imagen de Hispania que encontramos en otros historiadores romanos, especialmente los que escribieron en el Alto Imperio.

La obra de Pompeyo Trogo nos es conocida, sobre todo, por el epítome que realizó Justino en fecha incierta, entre el siglo II y el siglo IV d.C. y, como ocurre en estos casos, resulta difícil saber qué se puede atribuir al escritor original y qué al epitomador. En esta ocasión se han conservado los prólogos originales de los diferentes libros y gracias a ellos podemos saber hasta qué punto Justino es o no conservador respecto al original de Trogo. ${ }^{5}$ La estructura de la obra es geográfica, recorriendo los distintos territorios de Oriente a Occidente; por eso la laus Hispaniae se encuentra en el último libro, el XLIV, en el que los elogios de toda clase son continuados a lo largo del capítulo y se refieren a la bonanza de su clima ("de una parte por su moderado calor, de otra por sus lluvias bienhechoras y oportunas es fecunda en toda clase de frutos"), ${ }^{6}$ a la amplitud de sus recursos, capaces de alimentar no sólo a sus habitantes sino a Italia y a la ciudad de Roma (non ipsis tantum incolis, verum etiam Italiae urbique Romanae cunctarum rerum abundantia sufficiat), "a la abundante riqueza de sus minerales escondidos" (XLIV 1.6), a las ventajas de su geografía (XLIV 1.7: "el curso de los ríos no es torrencial y arrollador, de modo que causen perjuicios, sino que es lento y riegan las viñas y los campos; además, los estuarios del Océano son abundantes en peces, y los más también ricos en oro") o al carácter de sus hombres, preparados para el hambre, la fatiga e incluso la muerte (XLIV 2.1: corpora hominum ad inediam laboremque, animi ad mortem parati. Dura omnibus et adstricta parsimonia).

1 Aunque es asunto discutido, esta parece ser la fecha más probable y las otras propuestas no se distancian mucho de ella. CASTRO 1994, 25-27 propone entre el 14 y el 30 d.C.; Alonso NúÑEZ 1992, 12-15, entre el 2 a. C. y el 2 d.C.

2 Sobre la imagen de Hispania y las laudes en los autores clásicos, cf., entre otros, SCHULTEN 2004, 208209; FernáNDEZ-Chicharro de Dios 1948, 123-129; RonCERo 1993; GómeZ Espelosín et alii, 1994; CABRERO 2009, 19.

3 AlONSO NúÑ̃z 1988, 117 y 129.

4 De él se han ocupado, entre otros, GarCía y Bellido 1947, 281-284; TATE 1970, 173; Alonso NúÑEZ 1988; BLÁZquez 2006, 247-248; CABRERo 2009, 19.

5 AlONSO NuÑEz 1994, 110.

6 XLIV 1.4. hinc temperato calore, inde felicibus et tempestivis imbribus in omnia frugum genera fecunda est. Seguimos la edición de SeEL, 1986, y la traducción española de CASTRO, 1994. 
Destaca también el elogio particular de Viriato, en el que entre otras cualidades se subrayan su frugalidad y moderación, a la manera estoica: "A lo largo de tantos siglos no tuvieron ningún gran general salvo Viriato, quien durante diez años acosó a los romanos con victorias varias... Su valor y moderación fueron tales que, aunque venció frecuentemente a los ejércitos consulares, después de tan grandes acciones no cambió ni sus armas ni su vestimenta ni su modo de vivir... de manera que cualquier soldado raso parecía más rico que su general" (XLIV 2.7-8).

Como puede observarse, el capítulo tiene una voluntad laudatoria evidente y se refiere a aspectos muy distintos de Hispania: su clima, su geografía, sus recursos, sus hombres..., excepto el último párrafo, en el que, tal vez para enfatizar las buenas acciones de Augusto, encontramos una alusión poco benévola al carácter incívico de los hispanos, a los que se tacha de pueblo bárbaro y salvaje: "Y no pudieron aceptar el yugo de provincia dominada, antes de que César Augusto ... después de haberlos conducido con leyes a un modo de vida más civil, redujera a provincia este pueblo bárbaro y salvaje " (XLIV 5.8). ${ }^{7}$

Este tono elogioso referido a Hispania de Trogo-Justino nos hace enseguida recordar al otro gran epitomador latino, Floro, que en su Historia romana, se refiere a Hispania en distintas ocasiones en un tono de alabanza que también ha llamado la atención de los comentaristas de su obra. ${ }^{8}$ Ciertamente es muy notable su preocupación e interés por Hispania, puestos de manifiesto cada vez que hay un pasaje que habla de las guerras desarrolladas en nuestro país. Mezclada con los elogios, también hallamos en Floro esa concepción de Hispania como unidad territorial y potencialmente política que hemos visto en Trogo. Al comenzar la narración de las guerras celtíbero-lusitanas, dice: "Nunca concibió Hispania alzarse toda ella contra nosotros, nunca le resultó grato oponernos sus fuerzas ni tentar nuestro poderío o defender su propia libertad colectivamente... Sin embargo, quedó sitiada por los romanos antes de que se conociera a sí misma y fue la única de todas las provincias que tuvo conciencia de sus propias fuerzas después de haber sido vencida" (I 33.3-4). ${ }^{9}$

Resalta Floro la situación geográfica de Hispania, privilegiada para la defensa si hubiera estado unida políticamente, al estar rodeada por todas partes por el mar y los Pirineos: Alioquin ita undique mari Pyrenaeoque vallata est, ut ingenio situs ne adiri quidem potuerit (ibidem).

En otros pasajes destaca el valor de sus soldados. Al narrar la guerra de Sertorio, comenta: "Los valientes se entienden fácilmente con los valientes y nunca brilló más el valor del soldado hispano que con un general romano" (II 10.3) y subraya el carácter pacífico de sus pobladores: al finalizar su relato de las campañas de Augusto contra cántabros y astures, alaba la fidelidad de éstos y su carácter "más inclinado al arte de la paz": Hic finis Augusto bellicorum certaminum fuit, idem rebellandi finis

7 Nec prius perdomitae provinciae iugum Hispani accipere potuerunt, quam Caesar Augustus... populumque barbarum ac ferum legibus ad cultiorem vitae usum traductum in formam provinciae redegit

8 Cf., entre otros, Alba 1953, 131 y ss.; Straub 1990, 654 y ss.; Hinojo-Moreno 2000, 61 y ss.

9 Hispaniae numquam animus fuit adversum nos universae consurgere, numquam conferre vires suas libuit, neque aut imperium experiri aut libertatem tueri suam publice... Sed ante a Romanis obsessa est quam se ipsa cognosceret, et sola omnium provinciarum vires suas postquam victa est intellexit. Seguimos el texto latino de Seymour 1959 y la traducción española de Hinojo-Moreno 2000. 
Hispaniae. Certa mox fides et aeterna pax, cum ipsorum ingenio in pacis promptiore, tum consilio Caesaris (II 33.59). Un final que contrasta claramente con el que acabamos de ver en Trogo-Justino, donde se habla de pueblo bárbaro y salvaje. ${ }^{10}$

Sin duda, los mayores elogios se los lleva Numancia, por la defensa heroica de su ciudad y por la lealtad hacia sus aliados: "Numancia, así como en riqueza fue inferior a Cartago, Capua y Corinto, en fama, por su valor y dignidad fue igual a todas y, por lo que respecta a sus guerreros, la mayor honra de España... contuvo con cuatro mil celtíberos, durante once años, a un ejército de cuarenta mil, y no solo lo contuvo, sino que lo golpeó con notable dureza y le impuso infamantes tratados" (I 34.1-2), ${ }^{11}$ y un poco más adelante: “¡Cuán valerosísima y, en mi opinión, extraordinariamente dichosa ciudad, en medio de su desventura! Sostuvo con lealtad a sus aliados y contuvo durante mucho tiempo con una fuerza muy pequeña al pueblo reforzado por los recursos del orbe terrestre" (I 34.16). ${ }^{12}$

Igualmente encontramos elogios a la capacidad de sus caudillos más relevantes: Olíndico, "hombre extraordinariamente destacado por su astucia y osadía", Viriato, "hombre de sutilísima sagacidad... un Rómulo para Hispania", Megavárico, "valerosísimo".

Incluso hallamos en Floro críticas al comportamiento injusto de Roma con los hispanos, algo sumamente llamativo en un autor panegirista de la grandeza de Roma; hay críticas por su inaceptable declaración de guerra a los numantinos: Non temere, si fateri licet, ullius causa belli iniustior ("Difícilmente, si se me permite confesarlo, se podría hallar causa más injusta para una guerra"). Y continúa explicando: "Habían acogido a los segidenses, aliados y parientes suyos, fugitivos de las manos de los romanos. De nada sirvió su intercesión. Pese a que se habían mantenido lejos de toda participación en los enfrentamientos, recibieron la orden de deponer las armas..." (II 34. 3-4).También censura el ensañamiento en la destrucción de la ciudad: "por lo demás, [el pueblo romano], iniciado en la destrucción de ciudades por el incendio de Cartago, a las órdenes de Escipión, se enardeció también en su deseo de venganza..." (I 34.8) ${ }^{13}$ Igualmente, a propósito de la guerra de Sertorio, escribe: "La desgraciada Hispania sufría el castigo de la discordia entre los generales romanos" (II 10.8). ${ }^{14}$

El tono laudatorio de Trogo-Justino o la preocupación y afecto que demuestra Floro hacia lo hispánico son llamativos porque hasta aquí la historiografía romana es netamente nacionalista y parece tener poco interés en los pueblos que conquista. Alguna preocupación había en los Origines de Catón el Censor sobre ciertos pueblos itálicos

10 De la relación entre Trogo Pompeyo y Floro al tratar de Hispania se ocupa SALOMONE 1981, 52-53, quien subraya la dependencia de fuentes griegas de Trogo.

11 Numantia quantum Carthaginis, Capuae, Corinthi opibus inferior, ita virtutis nomine et honore par omnibus, summumque, si vero aestimes, Hispaniae decus... quattuor milibus Celtiberorum quadraginta exercitum per annos undecim sola sustinuit, nec sustinuit modo, sed saevius aliquando perculit pudendisque foederibus adfecit.

12 Macte fortissimam et meo iudicio beatissimam in ipsis malis civitatem. Adseruit cum fide socios, populum orbis terrarum viribus fultum tam parva manu aetate tam longa sustinuit.

13 ceterum duce Scipione, Carthaginis incendiis ad excidium urbium inbuto, tandem etiam in ultionem excanduit.

14 misera inter Romanos duces Hispaniae discordiae poenas dabat. 
e incluso hispánicos, pero la obra se conserva muy fragmentariamente y podemos decir que es una excepción en lo que se refiere a la preocupación por naciones distintas de la romana. Importaba, sobre todo, la historia de Roma, no la historia universal. No ocurre lo mismo con la historiografía griega de época helenística, que con frecuencia se ocupó de otros pueblos. En el caso de Iberia, los autores griegos se interesaron por el territorio hispano desde una perspectiva mítica y haciendo sobresalir los aspectos más exóticos. ${ }^{15}$ Sin embargo, Polibio, ciudadano romano de origen griego con una visión universal de la historia y que sabemos a ciencia cierta que estuvo en Hispania, no trasmite alusiones favorables al país, aunque en su narración de las guerras púnicas había muchas ocasiones para hacerlo. Desde luego, no pueden considerarse así los aislados pasajes en que el historiador griego describe los importantes recursos agrícolas y minerales de Hispania. ${ }^{16}$ Es más, en algún pasaje se alude a la perfidia de los celtíberos (X 6.2 y 7.1) ${ }^{17}$ y se critica la traición de Indíbil y Mandonio en un discurso de Escipión que insiste en otorgar la victoria sobre los cartagineses solo a los romanos, sin que hayan tenido nada que ver los pueblos hispánicos (XI 31.5-7). Por eso, estas innovadoras visiones sobre Hispania de Trogo-Justino y Floro nos exigen indagar sobre sus posibles orígenes y para ello nada mejor que empezar contrastando su imagen de Hispania con la que encontramos en los historiadores coetáneos.

Diodoro de Sicilia, autor griego del siglo I a.C., una generación anterior a Trogo, hace distintas alusiones a Hispania a lo largo de su obra, algunas de ellas positivas, sobre todo a propósito del valor de los guerreros celtíberos o baleáricos y también de la riqueza de su minería, ${ }^{18}$ pero su visión es más etnográfica que geográfica, pues se refiere a distintos pueblos de la Península y, en ocasiones, también se mencionan algunas costumbres un tanto bárbaras, que Diodoro parece censurar. ${ }^{19}$

Tito Livio sigue en su obra el camino marcado por sus antecesores analistas romanos. La historia se cuenta en función de Roma con notable despreocupación por los pueblos con los que entra en contacto, enemigos siempre, casi siempre bárbaros y muy frecuentemente pérfidos. En lo que se refiere a los hispanos, en la extensa narración de las guerras púnicas nada hay parecido a lo que hemos visto en Trogo-Justino o en Floro, a pesar de que gran parte del conflicto se desarrolla en el escenario hispánico. Hispania sigue considerándose una región muy alejada (cf. XXVII 40.5: "una de las guerras se realizaba en las regiones extremas de la tierra"), cuyos habitantes tienen costumbres bárbaras (XXVIII 1.8: "el campamento de los celtíberos estaba sin control y descuidado, como es propio de bárbaros, de reclutas y de los que no tienen

15 Gómez EsPelosín et alii, 1995, 104-108.

16 Sin embargo, FERnÁndez-Chicarro 1948, 39-46, incluye a Polibio entre los autores elogiadores de Hispania, basándose en textos aislados e ignorando los más críticos.

17 X 7.1: "cuando todavía estaba en Roma, había hecho averiguaciones, había investigado con detalle la traición de los celtíberos y la separación de las legiones romanas y dedujo que en todo ello radicaba la causa de los desastres sufridos por los hombres de su padre". Seguimos la traducción de BALASCH 1981-1983.

18 Sobre la destreza y el valor de los celtíberos (Biblioteca histórica V 33); sobre la riqueza de las minas de plata de los Pirineos (IV 35).

19 Sobre la costumbre de los celtíberos de cepillarse los dientes con orín (V 33), sobre la ciudad de los cemeletes, poblada de bandidos y prófugos (XXIX 28). Cf. Muñoz MarTín 1976. 
miedo porque están en su tierra"). ${ }^{20}$ Ningún vestigio de laus Hispaniae, aunque aquí y allá podamos encontrar elogios dispersos al valor militar de los guerreros de algunos pueblos o a las riquezas de ciertos lugares. ${ }^{21}$ Estas alabanzas se entremezclan con duras críticas a los hispanos, pues en algunos pasajes el territorio parece tener la consideración de tierra de traición. Así, cuando se censura la actitud de los celtíberos, que abandonan por dinero las tropas de Publio Cornelio Escipión padre, antes de enfrentarse a los cartagineses (XXV 33.1-8) o cuando se critica la deslealtad de Iliturgi y Cástulo con estas palabras: "algunas ciudades estaban tranquilas por miedo, conscientes de su culpa, más que por lealtad, de entre ellas eran especialmente notables por su tamaño y doblez Iliturgi y Cástulo" (XXVIII 19.1). ${ }^{22}$ También en la narración del levantamiento de Indibil y Mandonio, cuando habla abiertamente de criminal deslealtad: "el único vínculo que habían tendido de lealtad y amistad lo habían roto ellos con su crimen" (XXVIII 32.5).

En las Periochae encontramos algunas alusiones a Hispania, que confirman la tendencia de lo que encontramos en el texto conservado de Ab urbe condita. Se elogia la figura de Viriato: "Fue asesinado por unos traidores. Fue un gran hombre y un gran general, y durante los catorce años que hizo la guerra contra los romanos llevó las de ganar la mayoría de las veces" $(54.8)^{23}$; pero también se mencionan sus errores y sus derrotas (Ox. 53.170 y 54.185). En las alusiones a Numancia, hallamos, sobre todo, duras críticas a la incapacidad de los generales que hicieron la guerra antes de la llegada de Escipión (55 y 56. 3) y elogios a la determinación de este (48.17) y a la eficacia de sus métodos, ${ }^{24}$ pero no hay alabanzas explícitas a la heroicidad de los numantinos, aunque se trasmite que cuatro mil hicieron frente con éxito a cuarenta mil romanos (55.9). Al "hispánico" Sertorio se le considera causante de la guerra contra Roma (90.5) y se menciona su crueldad (92.4), pero también hay elogios a su capacidad como general. ${ }^{25}$

Con estos datos, resulta muy difícil sostener que Livio tuviera una actitud de simpatía hacia Hispania, como algunas veces se ha hecho para fomentar peligrosas ideas nacionalistas. ${ }^{26}$

Contemporáneo de Tito Livio y Pompeyo Trogo fue Estrabón, quien en el libro III de su Geografia se refiere a Iberia, considerándola también una unidad territorial,

\footnotetext{
20 illa altera soluta neglectaque, ut barbarorum et tironum et minus timentium quod in sua terra essent. Seguimos la edición de Walsh 1986 y la traducción de Ramírez de Verger y Fernández Valverde 1992.

21 Por ejemplo, esta alusión a la opulenta ciudad de Orongis: "la ciudad más próspera de aquellas regiones, a la que los bárbaros llaman Orongis... el campo es feraz; los habitantes obtienen también plata" (XXVIII 3.3).

22 quasdam civitates propter conscientiam culpae metu magis quam fide quietas ese apparebat, quarum maxime insignes et magnitudine et noxa Iliturgi et Castulo erant.

23 Seguimos la traducción de Villar Vidal, 1995.

24 "Ordenó que no dieran muerte a los forrajeadores porque si eran más numerosos consumirían antes el trigo" (57. 9).

25 "Un gran jefe que incluso frente a dos generales, Pompeyo y Metelo, fue vencedor la mayoría de las veces, cruel al tiempo que pródigo al final" (96. 4-5).

26 Tovar, 1943, defendió la simpatía de Livio hacia Hispania en una conferencia pronunciada en tiempos de Mussolini, que sirve para demostrar cómo se puede tergiversar la historia en función de determinados intereses ideológicos; en este caso, una supuesta hermandad italo-española que apoyara la alianza fascista de los gobiernos de la época.
} 
aunque luego hable con cierto detenimiento de sus regiones y pueblos más importantes. Estrabón, cuya fuente principal parece ser Posidonio de Apamea, ${ }^{27}$ se refiere a la riqueza agrícola, pesquera y mineral de Hispania: "A tanta riqueza como tiene esta comarca se añade la abundancia de minerales... la Turdetania y las regiones comarcanas abundan de ambas cosas [tierra fértil y minerales], y no hay palabra digna para alabar justamente esta virtud. Hasta ahora ni el oro ni la plata ni el cobre ni el hierro nativos se han hallado en ninguna parte de la tierra tan abundantes y excelentes" (III 2.8). ${ }^{28}$

También describe a los íberos como orgullosos y de carácter versátil y complejo, y cuando se refiere a los pueblos del norte indica que su rudeza y salvajismo se deben a sus costumbres guerreras y a su aislamiento (III 3.8). No obstante, podría afirmarse que los elogios son más numerosos que las críticas, por ejemplo cuando menciona a los lusitanos "diestros y hábiles en persecuciones" y a los pueblos del norte alabando su sobriedad en la comida y en la bebida (III 3.6-7).

Normalmente, hay acuerdo en afirmar que ese tono elogioso de Estrabón procede de Posidonio, fuente principal también de Diodoro Sículo y a quien en alguna ocasión se ha incluido entre los elogiadores de Hispania. ${ }^{29}$ Desde luego, hay base para la defensa de una actitud de simpatía hacia Hispania por parte de Posidonio e incluso se han propuesto diferentes razones para explicarla: actitud contraria al imperialismo romano, interés por demostrar sus teorías acerca de la influencia del clima sobre el carácter de los pueblos, etc. ${ }^{30}$ Es posible aceptar que el origen de algunos de los elogios hacia Hispania que encontramos en Estrabón -quizá también en Diodorotengan su origen en Posidonio, pero, en estos dos autores también hallamos pasajes poco laudatorios, sin que apreciemos esa decidida voluntad de alabanza que veíamos en Trogo-Justino o Floro.

Veleyo Patérculo, que probablemente murió en el año 31 d.C., escribió una Historia romana, en la que encontramos una referencia a Hispania, muy poco favorable y que merece la pena ser destacada por el contraste que supone con los pasajes de Trogo-Justino y Floro. Veleyo la escribe como colofón a la victoria de Augusto sobre cántabros y astures, y en ella se muestra el carácter belicoso de sus pueblos y los muchos quebraderos de cabeza que causó a Roma, de modo que la "pacificación" de Augusto podría interpretarse como un castigo por los problemas surgidos en su suelo. Desde el punto de vista formal llama la atención la reiteración del demostrativo illae para referirse a las provincias con un matiz claramente peyorativo que aumenta la sensación de encono hacia el territorio:

"Las Hispanias... fueron pacificadas llegando a su fin sus muchos combates de variada fortuna ... de tal manera se combatió en ellas con gran derramamiento de sangre por ambas partes que se hacía frecuente la lamentación por la pérdida de generales y ejércitos del pueblo romano, e incluso alguna vez pusieron en peligro la estabilidad

27 Cf. Zimmerman 1988.

28 Seguimos la traducción de GARCÍA y Bellido 1968, 86.

29 Fernández-Chicharro 1948, 48-54.

30 Cf. Alonso NúÑEZ 1979, 645-646. 
del dominio romano. Pues aquellas provincias (illae enim provinciae) se llevaron a los Escipiones, aquellas (illae) atormentaron a nuestros mayores con una afrentosa guerra de quince años contra el caudillo Viriato, aquellas (illae) hicieron estremecerse al pueblo romano con el terror de la guerra de Numancia. En ellas (in illis) el senado rompió el vergonzoso tratado de paz de Quinto Pompeyo y la afrenta aún más vergonzosa del general Mancino entregado en condiciones indignas. Aquella tierra (illa) se llevó a tantos hombres que habían sido cónsules o que habían sido pretores, y en la época de nuestros padres ensalzó tanto a Sertorio por sus campañas militares que durante cinco años no pudo decidirse si era más potente el ejército hispano o el romano y qué pueblo iba a obedecer al otro. Así es que César Augusto hace casi cincuenta años consiguió pacificar a estas provincias tan extensas, tan pobladas, tan fieras..." (II 90). ${ }^{31}$

En otros pasajes de su obra llama a Viriato "capitán de bandidos" y considera que la guerra contra él fue "triste y afrentosa" (II 1.3-4). Al referirse a Numancia minimiza la heroicidad de los numantinos aludiendo a la ignorancia de los comandantes romanos y a la indulgencia de la fortuna (ibidem).

Veleyo relaciona la revuelta civil surgida en Roma en el tribunado de Tiberio Graco con su participación en la guerra de Numancia a las órdenes de Mancino. El enfado porque no se hubiera respetado el tratado o el temor a sufrir la misma suerte que su jefe es lo que habría propiciado la propuesta de leyes tan revolucionarias:

"La entrega de Mancino provocó una disensión enorme en la ciudadanía. En efecto, Tiberio Graco, ... por quien, siendo cuestor, se había concertado ese tratado, molesto porque se había restado vigencia a un tratado gestionado por él o bien temeroso por las consecuencias de un juicio semejante y del castigo, nombrado tribuno de la plebe... se apartó de los buenos y prometiendo la ciudadanía a toda Italia, al mismo tiempo promulgando leyes agrarias, y aunque todos deseaban estabilidad, difundió inquietud por doquier y condujo al Estado a una situación extremadamente peligrosa y arriesgada" (II 2. 1-3). ${ }^{32}$

31 Hispaniae... multo varioque Marte pacatae ... per annos cc in his multo mutuoque ita certatum est sanguine, ut amissis populi Romani imperatoribus exercitibusque saepe contumelia, etiam nonnumquam periculum Romano inferretur imperio. Illae enim provinciae Scipiones consumpserunt; illae contumelioso xx annorum bello sub duce Viriatho maiores nostros exercuerunt; illae terrore Numantini belli populum Romanum concusserunt; in illis turpe Q. Pompei foedus turpiusque Mancini senatus cum ignominia dediti imperatoris rescidit; illa tot consulares, tot praetorios absumpsit duces, patrumque aetate in tantum Sertorium armis extulit, ut per quinquenium diudicari non potuerit Hispanis Romanisne in armis plus ese roboris et uter populus alteri pariturus foret. has igitur provincias tam diffusas, tam frequentis, tam feras ad eam pacem abhinc annos ferme L perduxit Caesar Augustus... Seguimos la edición de Stegmann de PritawaLd 1968 y la traducción de SÁnchez Manzano 2001.

32 Inmanem deditio Mancini civitatis movit dissensionem. Quippe Tiberius Gracchus... quo quaestore et auctore id foedus ictum erat, nunc graviter ferens aliquid a se pactum infirmari, nunc similis vel iudicii vel poenae metuens discrimen, tribunus pl. creatus,... descivit a bonis, pollicitusque toti Italiae civitatem, simul etiam promulgatis agrariis legibus, omnibus statum concupiscentibus, summa imis miscuit et in praeruptum atque anceps periculum adduxit rem publicam. 
En los Dichos y hechos memorables de Valerio Máximo, que vivió entre finales del siglo I a.C. y principios del I d.C. ${ }^{33}$ no hay tampoco elogios a Hispania. En las alusiones a la guerra de Numancia no se ensalza el valor de la ciudad y únicamente hallamos una agria crítica a sus habitantes por haber practicado el canibalismo: "Cuando hubieron consumido todo aquello que podía entretener su hambre, terminaron por alimentarse de cadáveres humanos. Por lo cual, una vez tomada la ciudad, se hallaron muchos que llevaban bajo sus vestidos trozos y miembros enteros de cuerpos humanos. En este caso, la necesidad no es una excusa, porque, si eran libres para morir, no tenían la obligación de sobrevivir bajo tales condiciones" (VII 6, ex. 2). ${ }^{34}$

El exemplum siguiente es un alegato todavía más duro contra los calagurritanos por la misma razón. ${ }^{35}$ En otro exemplum, al comentar la victoria de Escipión Emiliano termina de esta forma: "asoló a la orgullosa y audaz Numancia, destruyéndola con el fuego y convirtiéndola en un montón de escombros" (II 7.1). ${ }^{36}$ En su comentario de la muerte de Viriato se critica su asesinato, instigado por Servilio Cepión, pero no hallamos las alabanzas a las hazañas del caudillo lusitano que aparecen en otros autores (IX 6.4). Antes bien, en un pasaje en el que habla de Sertorio tilda a los lusitanos de pueblo "bárbaro, rudo y difícil de ser gobernado" (VII 3.6).

El geógrafo Pomponio Mela, que publicó su obra hacia el año 45 d.C., ${ }^{37}$ considera ya Hispania como una unidad político-geográfica y destaca la riqueza de sus recursos humanos y económicos:

"Hispania está envuelta por la mar en todas sus partes, excepto por el lado que confina con las Galias. En esta parte es muy estrecha, pero poco a poco se ensancha hacia Nuestro Mar y el Océano, a medida que avanza más y más hacia Occidente, donde alcanza su mayor anchura. Es abundante en hombres, caballos, hierro, plomo, cobre, plata y oro; y es tan fértil que, incluso en algunos lugares donde la falta de agua la hace estéril y pobre, produce, no obstante, el lino o el esparto". ${ }^{38}$

Aparte de este elogioso pasaje sobre sus recursos económicos, el resto de la obra del geógrafo hispano ${ }^{39}$ es muy descriptiva, sin que hallemos otros pasajes encomiásticos hacia su país de origen.

Interesante resulta también el testimonio del naturalista Plinio el Viejo (24-79 d.C.), quien hace numerosas alusiones a Hispania en su Naturalis Historia; en general, el texto de Plinio es muy descriptivo, con detalladas indicaciones geográficas,

33 Hay pocos datos para establecer una fecha segura, MARTín ACERA 1988, 25, sitúa su vida entre el último tercio del I y el año 35 d.C.

34 Seguimos en nuestras citas el texto latino de SHACKLETON 2000 y la traducción al español de MarTín ACERA 1988.

35 "La execrable impiedad de los habitantes de Calahorra, que se hallaban en una circunstancia parecida, superó la horrible obstinación de los numantinos...” (VII 6, ex. 3).

36 acrem illam et animosam Numantiam, incendiis exustam ruinisque prostratam, solo aequavit.

37 Se titula De Chorografia y es un epítome dividido en tres libros, de carácter divulgativo.

38 Cf. II 86. Traducción de GARCÍA y BELLIDo 1978, 29, donde pueden leerse en versión castellana todas las alusiones a Hispania de Pomponio Mela.

39 Nació en un pueblo cercano a Cádiz, en Tingentera, según confesión propia; cf. GARCía y BeLLido 1978, 19. 
menor número de datos etnográficos y abundantes referencias a sus recursos económicos. En el libro XXXVII se incluye este conocido pasaje laudatorio:

"Inmediatamente después [de Italia], y exceptuando las fabulosas regiones de la India, debo colocar a Hispania, al menos todo su borde costero; es, en verdad, pobre en parte, pero allí donde es fértil da en abundancia cereales, aceite, vino y caballos y metales de todo género, en lo cual la Galia va a la par; pero Hispania la vence por el esparto de sus regiones desérticas, por la piedra especular, por la belleza de sus colorantes, por su ánimo para el trabajo, por sus fornidos esclavos, por la resistencia de sus hombres y por su vehemente corazón". ${ }^{40}$

Este pasaje se incluye habitualmente entre las laudes Hispaniae, aunque el resto de citas de Plinio son descriptivas, sin que puedan apreciarse claras intenciones de elogio.

Sigamos ahora con el resto de historiadores del Alto Imperio más o menos coetáneos de Floro y de Justino, pues no sabemos con certeza en qué fecha vivieron estos dos autores, aunque al primero se le sitúa mayoritariamente en época del emperador Adriano y al segundo, como apuntábamos más arriba, entre los siglos II y IV d.C. En esta época es ya normal que Hispania fuese considerada una unidad no solo geográfica sino también política, pues tras las guerras cántabras, toda la península se convirtió en provincia romana $y$, a pesar de las distintas divisiones administrativas por las que atravesó a lo largo del Imperio, se la considera normalmente como un todo, al que se denomina Hispania o las Hispanias.

Antón (2006) se ha ocupado de las alusiones a Hispania en la obra de Tácito, que falleció en época del emperador Adriano (55-120 d.C.); en este trabajo se destaca la escasa atención que el historiador dedica a esta provincia y se concluye que quizá haya que entenderlo no tanto como indiferencia sino como señal de antipatía hacia los emperadores hispanos. Sin negar esta posibilidad, lo que a nosotros nos interesa aquí es destacar esa innegable desatención o indiferencia de Tácito hacia Hispania. ${ }^{41}$

Coetáneo aproximado de Tácito es el biógrafo Plutarco (aprox. 50-120 d.C.), en cuyas obras no hay importantes referencias a Hispania. El género literario, biografía, puede tener que ver en este silencio, pero, de todos modos, el desinterés de Plutarco por Iberia y el menosprecio por sus pobladores es tan evidente que ha llamado la atención de los especialistas ${ }^{42}$. Desde luego, la visión de sus biografiados Tiberio Graco y Sertorio, ambos populares, es altamente positiva en su obra, pero no hay valoraciones sobre las provincias y poblaciones donde transcurrió parte de la vida

40 Plinio, N.H. XXXVII 203. Seguimos la traducción de GARCíA y Bellido 1978, 200-202, donde pueden leerse el resto de comentarios de Plinio relacionados con Hispania.

41 ANTón 2006, 95: "la mención neutral y desapasionada de esta región podrían explicarse diciendo que el historiador no tenía ninguna necesidad de militar a favor de una provincia de la que eran originarios los emperadores. Sin embargo, creemos que el silencio o la indiferencia servían para celar su verdadera opinión sobre ella, ya que si al discreto papel que representa esta provincia en sus opera maiora unimos la imagen poco o nada encomiable de los personajes hispanos que se mencionan, la conclusión es que Tácito no sentía muchas simpatías hacia la provincia de la que al fin y al cabo procedían Trajano y Adriano".

42 Muñoz Gallarre 2007, 62-63. 
de los dos políticos romanos. Se juzga muy positivamente la inteligente actividad en la guerra de Numancia de Tiberio Graco: "Una vez que regresó a Roma, todo este asunto, como si fuera algo terrible y deshonroso para la ciudad, le acarreó acusaciones y reproches; pero los parientes y amigos de los soldados, que conformaban una gran parte del pueblo, corrieron en masa hacia Tiberio, imputando la vergüenza de lo sucedido al general y afirmando que gracias a Tiberio se había salvado tal cantidad de ciudadanos". ${ }^{43}$

Pero no hay ningún tipo de elogio a Numancia o a los numantinos. Tampoco en la vida de Sertorio se encuentran elogios hacia Hispania o los pueblos hispánicos, aunque la visión de Plutarco es muy favorable al político popular, considerado el más grande general de su época: "y se propagó totalmente hasta Roma que era el más hábil en manejar la guerra de los generales de entonces" (18.2). ${ }^{44}$

Nada relevante sobre Hispania encontramos en las biografías de Suetonio, coetáneo de Plutarco, tan solo algunas referencias contextuales que no revelan preocupación alguna por la provincia.

Muy interesante resulta el testimonio de Apiano de Alejandría que escribió una Historia de Roma en tiempos de los Antoninos (aproximadamente entre 95 y 165 d.C.), con estructura geográfica, al estilo de Trogo, en la que dedicó un capítulo a Iberia. Por supuesto, Apiano considera el territorio de la Península Ibérica como una unidad y dice al principio del capítulo: "La extensión de Iberia -a la que algunos ahora llaman Hispania, en vez de Iberia- es enorme e increíble como para tratarse de un solo país". ${ }^{45}$ Su visión es favorable a Hispania y a los pueblos y caudillos hispánicos. Al inicio de su relato sobre la Segunda Guerra Púnica, afirma: "Este país afortunado y lleno de grandes riquezas comenzaron a explotarlo los cartagineses antes que los romanos" (Iberia 3). ${ }^{46}$

Al tratar de Viriato, al que evidentemente considera un héroe, expresa estas sentidas palabras:

"Tan grande fue la nostalgia que de él dejó tras sí Viriato, un hombre que, aun siendo bárbaro, estuvo provisto de las cualidades más elevadas de un general; era el primero en todos en arrostrar el peligro y el más justo a la hora de repartir el botín. Pues jamás aceptó tomar porción mayor aunque se lo pidieran en todas las ocasiones, e incluso aquello que tomaba lo repartía entre los más valientes. Gracias a ello tuvo un ejército con gentes de diversa procedencia sin conocer en los ocho años de esta guerra ninguna sedición" (Iberia 75).

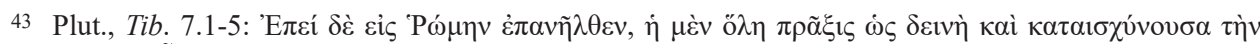

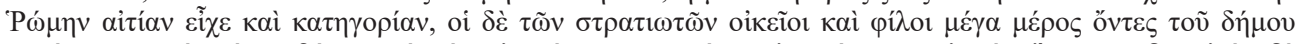

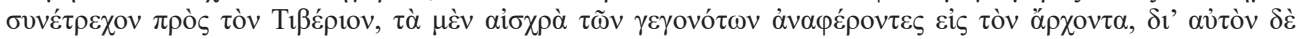
$\sigma \omega ́ \zeta \varepsilon \sigma \theta \alpha$ MARTíN-GonzÁLEZ GonZÁLEZ 2010.

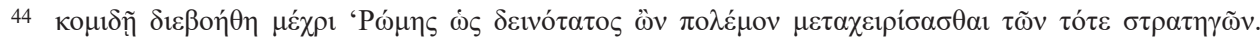
Seguimos el texto de Perrin 1959 y la traducción de Bergua et alii 2007.

45 Apiano, Sobre Iberia, 1. Seguimos la edición de WhITE 1964 y la traducción al español de SANCHO RoYo 1994.

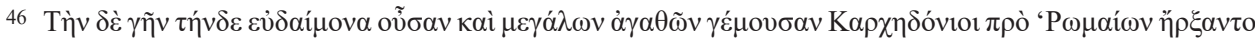
$\pi \circ \lambda v \pi \rho \alpha \gamma \mu \varepsilon \tilde{\mathrm{i} v}$. 
No son menos expresivas y sentidas sus palabras cuando se refiere a Numancia, al valor de sus hombres y a la increíble resistencia que mantuvieron frente a las tropas romanas, mucho más numerosas:

"Tan grande fue el amor a la libertad y el valor existentes en esta pequeña ciudad bárbara. Pues, a pesar de no haber en ella en tiempos de paz más de ocho mil hombres, ¡cuántas y qué terribles derrotas infligieron a los romanos! ¡Qué tratados concluyeron con ellos en igualdad de condiciones, tratados que hasta entonces a ningún otro pueblo habían concedido los romanos!... A mí, precisamente, se me ocurrió narrar estos sucesos relativos a los numantinos, al reflexionar sobre su corto número y su capacidad de resistencia, sobre sus muchos hechos de armas y el largo tiempo que se opusieron" (Iberia 97).

Más llamativo que estos elogios hacia Viriato y Numancia resultan las abiertas críticas contra Escipión por haber tomado la decisión de arrasar la ciudad antes de que el Senado romano se hubiera pronunciado, por su carácter vengativo y por cimentar su gloria sobre la ruina de algunas ciudades. Veamos el pasaje:

"Y la destrucción de Numancia, ciudad pequeña y de escasa población, sin que aún hubieran decidido nada sobre ella los romanos, ya sea porque lo considerara una ventaja para estos, o bien porque era un hombre de natural apasionado y vengativo para con los prisioneros o, como algunos piensan, porque consideraba que la gloria inmensa se basaba sobre grandes calamidades. Sea como fuere, lo cierto es que los romanos, hasta hoy en día, lo llaman "Africano" y "Numantino" a causa de la ruina que llevó sobre estas ciudades." (Iberia 98$).{ }^{47}$

En Apiano la causa de la discordia civil provocada por el tribuno de la plebe Tiberio Graco nada tiene que ver con su participación en la guerra de Numancia; fue la propuesta de ley agraria la causa de los disturbios (Guerras civiles I 9-10). Cuando se refiere a Sertorio, aunque censura su crueldad, elogia sus cualidades como general “...pues no había entonces otro general más hábil en la guerra ni más afortunado que este" (Guerras civiles I 112) ${ }^{48}$ y concluye el capítulo afirmando que la Guerra de Hispania no se habría acabado tan fácilmente si Sertorio hubiese seguido con vida (Guerras civiles I 115).

Refirámonos, por último, al testimonio de Dión Casio, que murió probablemente en la primera mitad del siglo III d.C., hacia el año 235. En su obra, Historia romana, libro XXII, hallamos un cuidado retrato de Viriato, que parece seguir el modelo del de Livio sobre Aníbal, y que en conjunto es una exaltación de sus virtudes como persona y como general (73.1). Es de destacar que en su inicio vuelva a aparecer la

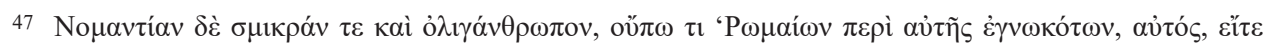

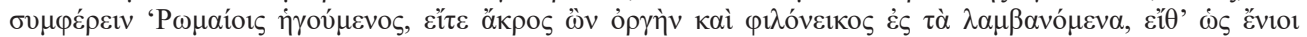

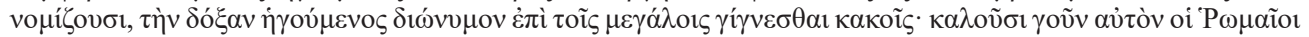

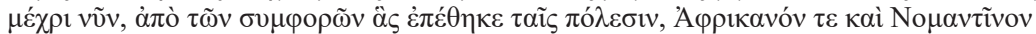

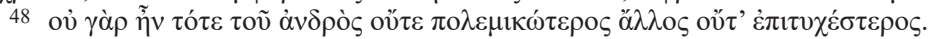


frase que hemos visto en otros autores (Floro, Periochae, etc), sobre su ascenso en la escala social, de pastor a general:

"Viriato, varón lusitano que era de muy oscuro linaje según opinión de algunos, por las notorias hazañas que realizó, pasó de pastor a bandido y después a general... Por ello resultaba capaz de soportar todo el calor y todo el frío del mundo, nunca sufrió por hambre ni se sintió vencido por ninguna otra carencia, pues siempre sacaba provecho por ser autosuficiente para todos las necesidades, de lo que en cada caso estuviera a mano, como si fuera lo mejor. Con ser tal su cuerpo, tanto gracias a la naturaleza como al ejercicio, resultaba muy superior en las virtudes del alma..." (XXII 73.1). ${ }^{49}$

Otro dato interesante en la obra de Dión es que vuelven a relacionarse las propuestas legislativas de Tiberio Graco con su participación en la guerra de Numancia a las órdenes del infortunado cónsul Mancino:

"Tiberio provocó la agitación entre los romanos, a pesar de su linaje... Tan pronto como se hubo alejado de la bondad, se topó, en contra de su voluntad, con la maldad. Así pues, cuando se le negó el voto por el triunfo por la victoria sobre los numantinos y él, que ya antes había esperado recibir honores por sus servicios, no obtuvo nada similar, sino que incluso corrió el riesgo de ser entregado, conoció que el asunto se había examinado, no según su virtud ni de acuerdo con la verdad, sino según el azar" (XXIV 83.1). ${ }^{50}$

El análisis de todos estos datos nos lleva a algunas consideraciones interesantes. En cuanto a la visión favorable a Hispania y a los hispanos, vemos que en los historiadores del Alto Imperio hay posturas claramente diferenciadas. Una alabanza continuada y nada casual en Trogo-Justino, al menos hasta el último punto de su capítulo, en el que alude a la victoria de Augusto sobre los "salvajes" cántabros y astures. Un elogio, interés y preocupación, casi sentimentales en Floro, llegando incluso a la crítica contra la injusticia y crueldad de los romanos; ello a pesar de ser un exponente claro de historiador panegirista de Roma y de sus empresas y conquistas. Una alabanza, sentida pero distinta, en la obra de Apiano, donde se mezclan los elogios a Hispania y los hispanos con duras y explícitas críticas al imperialismo romano.

En Estrabón también hay una visión favorable de Hispania, sobre todo al referirse a sus recursos económicos. Mucho más distanciada parece su alusión a los pueblos hispánicos, a los que se refería, como vimos, de una forma más descriptiva y analítica. Mela también ensalza las riquezas de Hispania, pero no puede hablarse propiamente de una laus, pues sus alusiones son bastantes descriptivas. Algo parecido a lo que se aprecia en Plinio el Viejo, algún pasaje elogioso mezclado con abundantes

49 Seguimos el texto griego de CARY 1968-1970 y la traducción de Plácido SuÁrez, 2004.

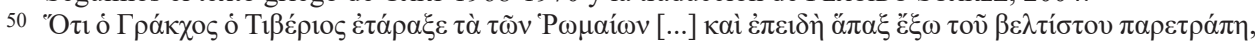

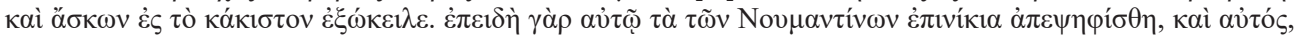

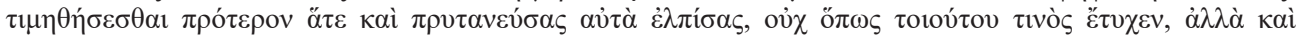

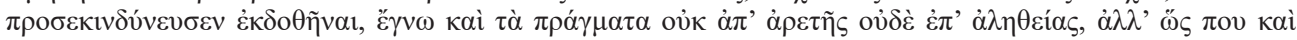

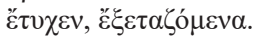


citas geográficas o etnográficas sin juicios de valor añadidos. Sin embargo, en bastantes ocasiones los textos de estos autores suelen incluirse entre las laudes Hispaniae. ${ }^{51}$ Quizá sea este un punto en el que convenga detenerse para establecer una diferenciación clara entre los autores que en su obra han realizado loas a Hispania. Nada tienen que ver las alabanzas continuadas a Hispania de Trogo, Floro o Apiano, donde se aprecia una voluntad laudatoria clara que reclama una explicación, con las loas de los autores tardo imperiales, que escriben con retórica panegirista de escuela al estilo de la época elogios a "su" emperador o a "su" patria, como es el caso de Pacato o San Isidoro, ${ }^{52}$ tampoco tienen que ver con los esporádicos pasajes elogiosos que encontramos en Diodoro, Estrabón, Mela o Plinio el Viejo, que no llaman particularmente la atención porque se incluyen en un discurso bastante objetivo, porque alternan con otros más críticos o porque son escasos, aunque quizá esos elogios puedan proceder de una fuente anterior que sí tuviera esa intención laudatoria, como tal vez sea el caso de Posidonio.

En el resto de autores no encontramos una visión hacia Hispania y lo hispánico como la que hemos visto en Trogo-Justino, Floro, Apiano y Estrabón, Mela o Plinio. Es verdad que en algunos historiadores leemos sentidas loas a Viriato, como en la periocha de Livio o en Dión Casio. Sin duda, el pasaje repetido con algunas variantes en distintos autores sobre el "ascenso" en la escala social de Viriato ("de pastor pasó a cazador, de cazador a bandido y de bandido a general") revela dependencia de una fuente importante, que muy probablemente es el propio Livio. ${ }^{53}$ Sin embargo, en otros pasajes Livio no muestra una actitud favorable a Hispania; ya vimos cómo en lo que se refiere a la participación en la guerra anibálica, se apunta en algunos lugares una cierta predisposición a la traición. Tampoco en Dión Casio hallamos otros pasajes favorables a Hispania. Y esa actitud, que podríamos calificar de indiferencia, es la misma que observamos en otros historiadores, como Tácito, Plutarco o Suetonio, aunque en el primero se podría hablar incluso de una disimulada antipatía.

Distinta es la posición de Veleyo Patérculo, en cuya obra hay un inusitado alegato contra Hispania por todos los problemas que causó a Roma a lo largo de la Historia. En ese sentido es, sin duda, el contrapunto de Floro. No hay, por supuesto, ningún elogio al heroísmo de los numantinos e incluso a Viriato se le llama "capitán de bandidos". En los exempla de Valerio Máximo el punto de vista también parece inclinarse más hacia la animadversión: ningún elogio a Viriato, sino críticas a los lusitanos, ninguna loa al valor de los numantinos, sino críticas por su antropofagia y todavía más duras contra los calagurritanos por idéntico motivo.

Así pues, y por lo que se refiere a la actitud hacia Hispania observamos una clara división entre los historiadores del Alto Imperio que va desde el interés y la simpatía hasta la indiferencia y la animadversión. En principio, la razón que puede explicar

51 SChulten 2004, 208 incluye a Estrabón y Mela entre los autores de laudes; sin embargo CABrero 2009, 23 insiste en el realismo de ambos geógrafos al tratar de Hispania, muy distinto de los elogios retóricos de otros autores.

52 Pacato (Panegírico a Teodosio IV 1. 815) y San Isidoro (Historia Gothorum 1.1-4).

53 El hecho de que aparezca en las Periochae y en Floro así parece indicarlo, aunque tampoco podemos descartar a Posidonio. 
estas actitudes, sobre todo las más centradas, puede ser una perspectiva metodológica distinta; la de los historiadores nacionalistas, que siguen el "romanocentrismo" de los analistas republicanos, frente a la visión "universalista" de otros autores -generalmente aunque no siempre de origen y lengua griega- que ponen su interés en otros países y pueblos, incluso cuando narran la historia de Roma. Digamos que en el primer bando encontraríamos a Livio, Diodoro, Plutarco, Tácito, Suetonio y Dión Casio, y en el otro, siguiendo la estela de Polibio y Posidonio, encontraríamos a Trogo y Apiano, y naturalmente a los geógrafos Estrabón y Mela y al naturalista Plinio el Viejo.

Sin embargo, la cuestión se complica un poco más a la hora de explicar simpatías evidentes o claros enconos. Digamos, antes de nada, que nos parece insuficiente explicar tan sorprendes elogios como producto de un tópico literario surgido en historiadores griegos de época helenística que intentaban atraer la atención de sus lectores con narraciones fabulosas sobre tierras muy lejanas. Tampoco parece muy acertado solucionar la cuestión indicando que de esa forma Roma se alaba a sí misma como artífice de la integración de la provincia en el Imperio. ${ }^{54}$ Es evidente que en algunos de los elogios hacia Hispania está implícita una dura crítica contra Roma. Ambas explicaciones pueden ser válidas para entender algunos pasajes concretos, pero de cualquier manera, parece más interesante observar caso por caso.

Quizá la alabanza más estudiada, por ser la más evidente, es la de Floro, que se ha atribuido al posible origen del escritor, apellidado quizá Anneo, ${ }^{55}$ y que o bien había nacido en Hispania o bien sus antepasados tenían ese origen. ${ }^{56}$ Parece claro que el origen de un escritor puede condicionar su perspectiva de los hechos históricos. La visión tan positiva que apreciamos en Trogo, sirva como ejemplo, sobre Marsella y su lealtad a Roma puede tener que ver con su origen, ${ }^{57}$ igual que el particular interés de Polibio por Megalópolis, su ciudad. ${ }^{58}$ También se ha apuntado la posibilidad de que la simpatía hacia Hispania estuviera relacionada con el intento del epitomador por congraciarse con los emperadores hispanos, Trajano y Adriano, bajo los cuales trascurrió su vida. ${ }^{59}$ Ambas razones no son excluyentes, por lo que podría pensarse que una y otra contribuyeron a ese sentido interés por lo hispánico que hallamos en su obra.

54 CABrero 2009, 18-19.

55 La cuestión ha sido muy discutida, sobre todo a partir de un códice vaticano que lo consideraba padre de Lucano y hermano de Séneca (Urb. Lat. 462). Cf. Hinojo-Moreno 2000, 11.

56 Straub 1990, 655, sin embargo, basándose en otros pasajes de su obra, defiende el origen africano de Floro: "parece mejor pensar en un P. Annius Florus, que, nacido en África, trabajó largo tiempo en Tarraco como rétor".

57 El propio Justino nos revela en XLIII 5.11 el origen de Pompeyo Trogo: “Al final del libro Trogo cuenta que sus antepasados toman su origen de los voconcios...". Los voconcios eran galos de la Galia suroriental. Alonso NuÑEz 1994, ha comentado su evidente predilección por la que consideraba su patria local, Massilia, y CASTro 1995, 9, cita los pasajes en que podemos apreciar su afecto por los galos.

58 Las alusiones a Megalópolis son frecuentes en la obra de Polibio, pero hay un pasaje absolutamente patriótico: “¿qué opinión deberemos tener, ciertamente, de los de Megalópolis? ¿Acaso no la mejor, la más noble?... (II 61.8-11).

59 Aunque el asunto es muy debatido no hay duda de que Floro vivió en época de los Antoninos y la mayoría de los especialistas se inclinan por datar la publicación de la obra bajo el reinado de Adriano. Cf., entre otros, Garzetti 1964, 138; Alonso Nuñez 1983, 26; Straub 1990, 665; Bessone 1993, 92; Galdi 
$\mathrm{Ni}$ el origen ni el paisanaje con el emperador pueden ser alegados en el caso de Pompeyo Trogo, que vivió bajo Augusto y sabemos que había nacido en la Galia Narbonense. ${ }^{60}$ Obviamente, la cuestión cambia radicalmente si pensamos que el autor del elogio hacia Hispania no es Trogo sino Justino. Desde luego, lo que parece muy claro es que los epitomadores, como Floro o Justino, en absoluto se consideraban meros "resumidores" de las obras de sus referentes Livio y Trogo. El caso de Floro es muy claro: el estilo es muy distinto y, desde luego, aquí y allá encontramos ideas que son propias del epitomador y no están en $A b$ urbe condita ${ }^{61} \mathrm{Su}$ distinto punto de vista respecto a Hispania es buena prueba de ello. ${ }^{62}$ No hay por qué pensar que el caso de Justino sea distinto, si, como parece, ambos autores cultivaron el mismo tipo de epítome, con autonomía temática y estética. ${ }^{63}$ Es verdad que en el caso de Justino no podemos contrastar con el texto de Pompeyo Trogo, y, en general, parece que Justino innova poco respecto del original, sobre todo cuando se abordan capítulos de los que tiene escasos conocimientos históricos, ${ }^{64}$ pero es lógico suponer que las cosas eran distintas cuando tenía capacidad y disposición para opinar y se ofrecía una buena ocasión para hacerlo, como sería el caso. Resulta revelador en este sentido que Schulten atribuya la laus de la que hablábamos al principio del artículo a Justino y no a Trogo, ${ }^{65}$ como se ha empezado a hacer desde hace tiempo, sin muchas razones a nuestro juicio, pues a nadie se le ocurre atribuir a Livio lo que dice Floro.

Quizá la visión que tenía Trogo de Hispania era favorable, como la que apreciamos en Estrabón y Mela, y teniendo como base las opiniones de Posidonio, ${ }^{66}$ pero el énfasis, ese evidente tono laudatorio, puede haberlo puesto Justino, en un intento de hacerse agradable a su emperador, Adriano con toda probabilidad, pues resulta muy aventurado proponer un origen hispánico para Justino solo a partir de este elogio. ${ }^{67}$ No hay que olvidar, además, ese final del capítulo, en el que el autor -en este caso podríamos pensar en un Trogo no matizado por Justino- alude a las conquistas de Augusto y se refiere al conjunto de los hispanos como pueblo bárbaro y salvaje.

La visión de Apiano puede explicarse también como un intento de halagar a la nacionalidad hispana de Trajano y Adriano, bajo la que trascurrió, según todos los indicios, parte de su vida. Ahora bien, en los elogios a Numancia y Viriato de Apiano

1922, 46. Un resumen sobre la cuestión y los distintos argumentos esgrimidos para la datación en HiNojoMORENO 2000, 20-29.

60 Parecen bastante seguros los datos que confirman que Trogo vivió en época del emperador Augusto, cf. CASTro 1995, 25-27.

61 Cf. Hinojo-Moreno 2000, 33-42; Moreno 1999.

62 Cf. Zancan 1942, 59-61.

63 Cf. Franga 1988, quien defiende la unidad estructural de los resúmenes históricos de Veleyo, Floro y Justino, historiadores que hicieron evolucionar un género, básicamente técnico, hacia formas más estéticas y personales.

64 El tema ha sido ampliamente debatido, cf. CASTro 1995, 9-15; también Alonso NuÑEZ 1992, 24 y ss.

65 SCHULTEN 2004, 209.

66 No se conocen las fuentes de Trogo, aunque se supone que la inmensa mayoría eran de origen griego. Cf. Alonso NúÑEz 1992, 16. Las referencias a la bondad del clima en Hispania, apoyarían la hipótesis de que Posidonio está en la base de las informaciones de Trogo sobre la Península.

67 No parece posible con los datos que tenemos establecer el lugar de nacimiento de Justino, aunque a partir de determinadas alusiones y por sus rasgos lingüísticos se han propuesto con escaso fundamento un posible origen galo o africano. Cf. CASTRO 1995, 9. 
hemos visto entremezclarse las críticas al imperialismo de los romanos, incluso a un hombre tan reputado como Escipión Emiliano, cuya actitud brutal contra Cartago y Numancia Apiano no parece comprender. Tomó la decisión de destruir Numancia antes de que el Senado se hubiera pronunciado e incluso Apiano muestra su extrañeza porque los romanos le otorguen el nombre de Africano y Numantino por semejantes proezas. Recordemos: "Sea como fuere, lo cierto es que los romanos, hasta hoy en día, lo llaman 'Africano' y 'Numantino' a causa de la ruina que llevó sobre estas ciudades". Este "antirromanismo" de Apiano es muy reconocible en otros pasajes de su obra, por ejemplo, cuando cuenta la derrota de los romanos en Caudium frente a los samnitas y en otros $^{68}$. De modo que nos atreveríamos a decir que en este caso la simpatía de Apiano hacia Hispania tiene más que ver con su censura del imperialismo romano que con su intento de congraciarse con el emperador de turno; en cierto modo, en la misma línea ideológica que, según se ha apuntado, pudo tener Posidonio. ${ }^{69}$

Tratemos ahora de la antipatía hacia Hispania. ¿Cómo explicar, particularmente, la animadversión evidente en Veleyo y en menor medida en Valerio Máximo? Tal vez, en este caso, la razón también pueda ser ideológica. Según Veleyo, las leyes reformistas de Tiberio Graco tienen su origen en la frustración de Tiberio por su mala experiencia en Numancia a las órdenes de Mancino. Esta idea, se repite, como hemos visto, en Dión Casio y evidentemente tiene su origen en los círculos optimates conservadores romanos; no es aventurado suponer que estuviera en Livio ${ }^{70} \mathrm{y}$ aparece claramente en Cicerón: Sed eorum alter (Ti Gracchus) propter turbulentissimum tribunatum, ad quem ex invidia foederis Numantini bonis iratus acceserat, ab ipsa republica est interfectus (Brut. 103). ${ }^{71}$ Un artículo del profesor Gregorio Hinojo, ${ }^{72}$ ponía ya en evidencia el distinto tratamiento que se daba a los tribunos en estos tres autores, Veleyo, Valerio Máximo y Floro, señalando esas dos tendencias ideológicas en la historiografía imperial, según su posición más o menos favorable a los políticos "populares". Los autores más críticos con la figura de Tiberio Graco son, sin duda, Veleyo y Valerio Máximo, que en distintos pasajes de sus obras arremeten con dureza contra el político reformista, ${ }^{73}$ mientras que Floro es mucho más comprensivo con las propuestas de Tiberio Graco en línea con el punto de vista que nos trasmite Plutarco en su biografía del tribuno. ${ }^{74}$ Apiano también se muestra favorable al tribuno. ${ }^{75} \mathrm{De}$

68 Cf. Apiano, Sam. 5. También en Gall. 2-3, a propósito de la toma de Roma por los galos en 396 a.C. Sobre el particular, vid. CASCón 2007, 134-137. WulfF-AlOnSo 1986, 750, comenta la simpatía de Apiano por la causa de los aliados itálicos en su guerra contra Roma, "a lo que a lo mejor no era ajena su propia posición de griego y ciudadano romano al servicio del Imperio”.

69 Cf. GabBa 1974, 635-637.

70 Las Periochae (LX-LXI), que hablan de tribunatus seditiosus, furor graquianus y leges perniciosae revelan claramente la animadversión de Livio.

71 Cf. Hinojo 1986-1987, 4; también, Murray 1966, 297.

72 Cf. Hinojo 1983.

73 Cf. Veleyo Patérculo, II 2.1; II 6.1; etc. Valerio Máximo, I 4.2; III 2.17; IV 7.1; V 3.2e; etc.

74 Cf. CASCón 1994, 460.

75 Guerras civiles I 17: "De esta forma, Graco, el hijo de aquel Graco que fue dos veces cónsul, y de Cornelia, la hija de aquel Escipión que abatió la hegemonía cartaginesa, pereció mientras era aún tribuno, en el Capitolio, por causa de un proyecto excelente perseguido de forma violenta. Y este crimen odioso, el primero que tuvo lugar en la asamblea pública...". 
manera que apreciamos una cierta coincidencia en este punto: historiadores favorables a Tiberio Graco, tienen simpatía por Hispania; los contrarios a Tiberio, tampoco ven con buenos ojos a los hispanos. En realidad, podría pensarse que los más exaltados panegiristas romanos, conservadores y nacionalistas, asocian el territorio hispano a las revueltas "populares" de Tiberio Graco y Sertorio. La primera surge, según ellos, por la frustración de la derrota en Numancia del primero; la segunda creció gracias al apoyo que dieron a la revuelta los pueblos hispánicos. En este sentido, Apiano, aun censurando la crueldad de Sertorio, lo considera el mejor general de su tiempo y cree que, si no hubiera sido asesinado traidoramente por los suyos, la guerra se habría prolongado mucho más. Floro, por su parte, da una visión también positiva de Sertorio como hombre valiente y gran general, sin llegar a la visión más laudatoria de la vida plutarquea.

En definitiva, esta revisión de los textos de los historiadores altoimperiales referida a Hispania nos permite extraer importantes conclusiones:

1) Las causas de la simpatía o animadversión hacia Hispania pueden tener que ver con el origen del escritor o con el intento de simpatizar con un determinado emperador, pero también con la posición ideológica del historiador, ya tenga una óptica "universalista" o nacionalista de la historia, sea o no crítico con el imperialismo romano y simpatice más o menos con la causa de políticos populares, como Tiberio Graco o Sertorio.

2) Esta diferente visión de Hispania viene a apoyar la idea de que en el Alto Imperio existieron dos corrientes historiográficas claramente diferenciadas, donde no solo una perspectiva universal se opone a la nacionalista, sino que subyace también el viejo antagonismo entre optimates y populares. En este sentido Hispania podría ser mal vista por los más conservadores como territorio “popular", lo que podría explicar la visión negativa de Veleyo Patérculo o Valerio Máximo y la simpatía de Apiano.

3) El encomiástico tono del texto de Justino nos hace pensar como muy probable que el epitomador trasformara decisivamente el texto de Pompeyo Trogo, con el fin de aumentar el elogio de Hispania y así agradar a algún emperador hispano, Trajano o Adriano; seguramente el texto de Trogo contenía ya buenas noticias sobre Hispania, tomadas de Posidonio, pero esa decidida y continuada alabanza de la provincia sería obra de Justino. Esta posibilidad vendría a apoyar las tesis de los que defienden una datación temprana de la publicación del epítome, en la primera mitad del siglo II.

\section{Bibliografía}

Alba, V. (1953): La concepción historiográfica de Lucio Anneo Floro, Madrid.

Alcalde Martín, C.—González González, M. (2010): Plutarco. Vidas Paralelas, VIII, Madrid.

Alonso NúÑEZ, J. M.

(1979): “Les informations de Posidonius sur la péninsule ibérique”, L'Antiquité Classique 48.2, 639-646.

(1983): Die politische und soziale Ideologie des Geschichtscreibers Florus, Bonn. 
(1988): "Pompeius Trogus on Spain", Latomus 47.1, 117-130.

(1992): La Historia Universal de Pompeyo Trogo, Madrid.

(1994): "Trogue-Pompée et Massilia (Justin, Epitoma XLIII 3.4-XLIII 5.10)", Latomus $53.1,110-117$.

AnTón, B. (2006): "La linguae continentia de Tácito: Los Antoninos e Hispania", Cuadernos de Filología Clásica, Estudios Latinos 26.1, 77-99.

Balasch Recort, M. (1981-1983): Polibio. Historias, Madrid.

Beltrán, F. — Piña, F. (1994): “Roma y los Pirineos. La formación de una frontera”, Chiron 24, 103-133.

Bergua J.- Bueno, J - J. M. Guzmán, (2007): Plutarco. Vidas paralelas, VI, Madrid.

Bessone, L. (1993): "Floro un retore storico e poeta", Aufstieg und Niedergang der Romische Welt II 34, Berlin-New York, 80-117.

BLÁzquez, J. M. (2006): “La Hispania en época de Augusto vista por los escritores contemporáneos", Gerión, 24.1, 237-249.

Cabrero Piquero, J. (2009): “La visión de Hispania en las fuentes clásicas”, [en] J. Andreu - J. Cabrero - I. Roda (eds.), Hispaniae. Las provincias hispanas en el mundo romano, Tarragona, 17-28.

CARY, E. (1968-1970): Dio's Roman History, 9 vols., Loeb, London-Cambridge.

CAscón, A. (1994): “¿Plutarco fuente de Floro?”, [en] M. García Valdés (ed.), Estudios sobre Plutarco: ideas religiosas, Madrid, 455-466.

CAscón, A. (2007): "Escritores griegos y latinos ante episodios legendarios de la historia de Roma”, [en] A. Sánchez - J. B. Torres - R. Martínez (coords.), De Grecia a Roma y de Roma a Grecia. Un camino de ida y vuelta, Pamplona, 129-142.

Castro Sánchez, J. (1995): Justino. Epítome de las Historias Filípicas de Pompeyo Trogo, Madrid.

Domínguez Monedero, A. (1983): “Los términos ‘Iberia’e ‘iberos’ en las fuentes grecolatinas. Estudio acerca de su origen y ámbito de aplicación”, Lucentum 2, 203-224.

Fernández-Chicharrode Dios, C.(1948): Laudes Hispaniae (Alabanzas de España), Madrid.

FrangA, L. (1988): “Á propos de l'epitomé de Justin”, Latomus 47, 868-874.

GABBA, E. (1974): “Storiografia greca e imperialismo romano (III-I a. C.)”, Rivista Storica Italiana 86, 625-642.

GALDI, M. (1922): L’Epitome nella letteratura latina, Nápoles.

GARCÍA y Bellido, A. (1968): España y los españoles hace dos mil años, Madrid, (1ª edición, 1945).

(1978): La España del siglo primero de nuestra era (según Pomponio Mela y Gayo Plinio), Madrid, (1 ${ }^{\text {a }}$ edición, 1947).

Garzetti, A. (1964): "Floro e l'età adrianea", Athenaeum 42, 136-156.

Gómez Espelosín, F. J. — Pérez Largacha, A. —Vallejo Girvés, M. (1995): La imagen de España en la Antigüedad clásica, Madrid.

Hinojo, G. - Moreno, I. (2000): Floro. Epítome de la Historia de Tito Livio, Madrid.

Hinojo, G. (1983): "Juicio de los historiadores imperiales sobre los Graco (Val. Máximo, V. Patérculo y Floro)", Helmantica 34, 293-308. 
Hinojo, G. (1986-1987): “Los juicios de Cicerón sobre los Graco”, Studia histórica. Historia antigua 4-5, 101-109.

Martín Acera, F. (1988): Valerio Máximo. Hechos y dichos memorables, Madrid.

Moreno Ferrero, I. (1999): “Intertextualidad y tradición en la época imperial: Los prefacios de Livio y Floro", [en] Mª C. Álvarez - R. Ma Iglesias (eds.), Contemporaneidad de los Clásicos en el umbral del Tercer Milenio, Murcia, 613-621.

Muñoz Gallarte, I. (2008): “Características del ethos ibérico en Plutarco”, Ploutarchos 5, 43-64.

Muñoz Martín, M. N. (1976), España en la Biblioteca Histórica de Diodoro Sículo, Granada.

Murray, R. J. (1966): “Cicero and the Gracchi”, TAPhA 97, 297.

PERRIN, B.

(1949): Plutarch's Lives, X, Tiberius and Caius Gracchus, Cambridge-London.

(1959): Plutarch's Lives, VIII, Sertorius and Eumenes, Cambridge-London.

Plácido SuÁrez, D. (2004): Dión Casio. Historia romana, Madrid.

Ramírez de Verger, A. — Fernández Valverde J. (1992): T. Livio. Ha de Roma. La Segunda Guerra Púnica, vols.1-2, Madrid.

Roncero LóPez, V. (1993): "Las Laudes Hispaniae de San Isidoro a Quevedo", Analecta Malacitana 16.1, 81-92.

Salomone Gaggero, E. (1981): Epitome di storia romana, I Classici di Storia, vol. XIV, Milano.

SÁnchez Manzano A. (2001): Veleyo Patérculo. Historia romana, Madrid.

SAncho Royo, A. (1994): Apiano. Historia romana, Madrid.

Schulten A. (2004): Hispania. Geografía, Etnología e Historia, Sevilla (1ª edición, 1915).

SeEl, O. (1985): M. Iunani Iustini, Epitoma historiarum philippicarum Pompei Trogi, Stuttgart.

Seymour Forster, E. (1959): Lucius Annaeus Florus. Epitome of Roman history, LondonCambridge.

Shackleton Bailey, D. R. (2000): Valerius Maximus. Memorabile doings and sayins, Cambridge-London.

Stegmann de Pritawald, C. (1968): C. Veleii Paterculi ex Historiae romanae libris duobus quae supersunt, Stuttgart.

Straub, J. A. (1990): "Conciencia de Imperio y sentimiento nacional en las provincias romanas. Hispania y el Imperio Romano en la concepción de Floro", [en] Cristianismo y aculturación en tiempos del Imperio romano VII, Murcia, 649-667.

TATE, R. (1970): Ensayos sobre la Historiografía Peninsular del siglo XV, Madrid.

Tovar, A. (1943): “España en la obra de Tito Livio”, Quaderni dell'Instituto italiano di cultura in Spagna 7.

Villar Vidal, J. A. (1995), Tito Livio. Periocas y Fragmentos. Libro de los prodigios, Madrid.

Walsh, P. G. (1986): T. Livius. Ab urbe condita. Libri XXVIII-XXX, Leipzig.

White, H. (1964): Appian's Roman History, 4 vols., London-Cambridge.

WulfF-Alonso, F. (1986): “Apiano: la colonización romana y los planes de Tiberio Graco”, Latomus 45.4, 731-750.

ZANCAN, P. (1942): Floro e Livio, Padova.

Zimmerman, R. (1988): "Posidonius und Strabo", Hermes 23, 103-130. 